\title{
Discussion on Neurobiological and Clinical Aspects of Postural Control in Motor Behavior
}

\author{
A. Gramsbergen and M. Hadders-Algra
}

University of Groningen, $9713 \mathrm{AV}$ Groningen, the Netherlands

\begin{abstract}
Albert Gramsbergen (Groningen, the Netherlands)
\end{abstract}
This special issue contains the contributions of the invited speakers to the international meeting on "Posture in the Picture, on the relevance of postural control in children with developmental disorders". During the meeting typical development of postural control was discussed from birth until adolescence, biodynamical aspects were considered, as well as phylogenetical aspects of postural control during erect gait. Physiologists, movement scientists, and anatomists discussed the roles of the corticospinal system in man, the cerebellum, and the basal ganglia in the development of postural control. During the meeting, vivid discussions emerged between these scientists and those who are involved in analyzing the problems in postural control in children with motor impairments, and scientists involved in designing effective therapies for children with dysfunctional postural control. The meeting was concluded by an organized and structured discussion in which a few of the most important issues were reconsidered. This discussion made it clear that strong cooperation is urgently needed between those involved in the analysis and therapy of motor impairments in children and basic scientists studying postural control from a theoretical perspective or performing experimental research in animals.

The questions from the audience during this meeting were collected and organized into clusters and brought forward to a panel of the invited speakers. The discussion was taped, edited, and authorized by the speakers.

\section{REFERENCE FRAMES}

Mijna Hadders-Algra (Groningen, the Netherlands)

One of the recurring issues in this workshop on postural control was the concept of reference frames. The question is do we need a reference frame in order to control our posture? Do we have one reference frame or a repertoire of reference frames? A related question is what actually is the goal in postural control? Is the goal to prevent us from falling or is it used to stabilize our heads in space? Nowadays the trend in physical therapy is functional goal setting. So what is the goal as far as postural control is concerned?

\section{Marjorie Woollacott (Eugene, Oregon, USA):}

We have to realize that basically there are two goals in postural control. One is the orientation in space which relates to the head position directing towards a specific target or to the horizon. The other is maintaining the center of mass within the basis of support or moving effectively towards a new basis of support. So within the scope of physical therapy, clearly we have to look at the goal in a specific task and make sure that we apply a therapy to have the child reach that goal within a task.

Mijna Hadders-Algra (Groningen, the Netherlands)

Eva Brogren Carlberg showed us a film of a girl with cerebral palsy (CP), throwing a bean-bag. 
We clearly saw in the film that her head was not stabilized while she threw the bean-bag. Would that mean that there is a priority in goals and that the girl only was able to successfully accomplish the task of throwing the bean-bag when she did not pay too much attention to the position of the head? Could there be a priority in postural goals: the first being 'not to fall' and the second 'head stabilization in space'?

\section{Eva Brogren Carlberg (Stockholm, Sweden)}

I think you may be right. Her goal was to hit the pole with the bean-bag: one could say that she used an allocentric reference frame and all motor abilities to accomplish that task. She clearly showed a symmetric tonic neck reflex and that was the way for her to stabilize the trunk and thus to be able to make a movement at the same time.

\section{Susan Harris (Vancouver, Canada)}

When I was a young clinician taking the NeuroDevelopmental Treatment (NDT) course, the instructors explained that lack of adequate postural control mechanisms in children with CP, e.g. while sitting in a seat and working on their schoolwork, meant that they-unlike other children-would have to think about maintaining their balance on their seat, as well as on concentrating on their schoolwork. Obviously, these are two sets of things to think about. I would think that when it is important for the child to do her schoolwork that either you might change the environment by giving him an adapted seat, or else train her to have better postural control during the task.

\section{Christine Assaiante (Marseille, France)}

Coming back to the question, I think that for the control of balance it is important to consider a frame of reference. On the basis of such frames of reference, movements are performed and postural adjustments are organized. Reference control is effected by the stabilization of the body segments in relation to each other. When standing, a frame of support is organized and then the segmental control is relatively simple, but during movements postural control has to be maintained during the movement. Then, the pelvis, the head, and also the trunk and shoulders should be controlled in order to making a movement possible (Assaiante, this issue).

\section{Hans Forssberg (Stockholm, Sweden)}

For the sake of the discussion, I want to advocate another opinion. Reference frames just fit into a way of thinking. You could consider it a set of words with which we try to understand the nature of po stural control. And then, obviously, reference frames do not apply exclusively to postural stability but to all parts of the body and the extremities including the fingers. So talking of reference frames reflects a way of thinking of the processing in the CNS rather than that such mechanisms really exist in the CNS.

\section{Luba Zuk (Tel-Aviv, Israel)}

I agree only to some extent with Dr. Forssberg as still, I think, the brain needs a sort of a reference frame in order to make, what you might call the transformations from the visual system to the proprioceptive system in order to plan a movement. When throwing a ball, we have to know how far we should throw it, in what direction we should throw it and then we should recruit the force to accomplish that. So I think we not only need to control the head position, trunk, and in fact all the parts of our body but we also need the visual perception and the transformations to orderly and adequately plan the movement, in order to achieve what we want to. 


\section{Marjorie Woollacott (Eugene, Oregon, USA)}

Here I would like to add that I noticed that in the studies on postural control performed so far, little attention has been paid to somatosensory impairments including visual and vestibular impairments. As the sensory impairments might be crucial underlying factors to the actual motor impairments, assessment of the sensory problems would be a most important thing to add to our future studies.

\section{CLINICAL ASSESSMENT OF QUALITY OF POSTURAL CONTROL}

Mijna Hadders-Algra (Groningen, the Netherlands)

Another question which has been raised by the audience is the following. Is there actually a clinical tool with which we can assess the quality of postural control?

\section{Laila de Groot (Amsterdam, the Netherlands)}

I think it will turn out to be extremely difficult to design an effective method to assess the quality of postural control. In the past, mainly the static component of posture has been considered and it seems relatively easy to score deviations in that sort of control. However, the dynamic aspect of postural control probably is far more important and disentangling the movement as such from the dynamic component of postural control will be very difficult.

\section{Tatjana Velickovic (Ljubljana, Slovenia)}

It might well be that a variety of postures and movement patterns, perhaps in a stylized setting, and recorded on video tape might lend to a qualitative assessment, in a what we call a Gestalt Perception-type of approach.

\section{Eva Brogren Carlberg (Stockholm, Sweden)}

The Berg Balance Scale (1995) that has been adapted for children could be of some help. But, indeed, there are only few other instruments to assess postural control and I think what we could do is to pick out some of the items of the Gross Motor Function Measure (GMFM; Russell et al. 2002) which are more balance oriented. Obviously, for children with milder motor disorders, e.g. children who are classified as level I and II in the Gross Motor Function Classification System (GMFCS, Palisano et al. 1997), you could use parts of the Movement ABC (Henderson \& Sugden, 1992) or the Bruininks-Oseretsky-test (Bruininks, 1978). But in general, I think it really would be worthwhile to develop a new instrument to assess postural control that might include some measures from existing methods and some new tests.

\section{Andrew Gordon (New York, USA)}

What has come across in this panel is that there are not only static aspects in postural control, but also dynamic aspects, and I guess, there is not one measuring instrument that covers these different aspects, although that is what we need. I could imagine that an instrument is devised that not only includes some clinical measures, analogous to those in the Berg Balance Scale but also to look at postural control during standing or sitting and sway during those static postures. In addition, some active control tasks should be included, much like those that Marjorie Woollacott has described in her contribution (Woollacott, this issue) and perhaps also some destabilization tests, e.g. in which children reach forward and where you look at anticipatory postural adjustments.

\section{Beatrijs Vereijken (Trondheim, Norway)}

There are several clinical instruments available to assess postural control but the problem is that 
the results of different postural control tests do not correlate well with each other. That actually is the main problem. Each of these tests measures different aspects, and we do not know well enough what we are looking at or how these different aspects are related to each other.

\section{Susan Harris (Vancouver, Canada)}

In line with what I said before (and from a single subject research perspective), you should consider what it is for each child in his or her postural control that the therapist hopes to change. Secondly, what is most important to the child should be considered in developing an individual therapy objective. From this perspective, measuring the abilities of a particular child would be far more important than using some scale that might not have specific applicability to your individual client. Far too infrequently, we look for the most effective outcome measures of individual behaviors. An approach with a measurable therapy objective seems important in this respect. I would think that would be more important than a broader scale.

\section{Hans Forssberg (Stockholm, Sweden)}

I think, the old way of thinking was that postural control is one component in movement control and voluntary control of extremity movements another. To my opinion, that is too simple. The task of the CNS is to perform a movement. What you may see in a child with $\mathrm{CP}$ before treatment is that the child manages to perform a movement with the whole body, while after successful treatment, the child stabilizes the body and performs the motor task in another and more efficient way. This illustrates that the central nervous system (CNS) is continuously integrating and stabilizing all the elements of a movement. In other words, posture and movement are not organized in a hierarchical way but they are integrated all the time.
An important research task for the future is to understand the relations between the two main sensory systems, the body centered system or proprioceptive system if you wish, and the other, which calibrates the body to the outside world, in which the visual system plays a dominant role. A major challenge for the CNS is to make the appropriate transformations from the information processed by the visual system to the information gathered by the body-centered system in order to make accurate movements.

Returning to the question of clinical assessment of postural control, we have to realize that the movement itself cannot be separated from postural control. But what we could do in our tests is to evaluate the reactive postural reactions when you are stabilizing the body or to test reactions when you are moving only one joint. So I agree with Dr. Harris, Dr. Gordon and others that we have to develop goal achievement scales with respect to postural control. Sterotyped batteries are not really what we are aiming for, though these might be useful as a basis for further investigations.

\section{Sara Capelovitch (Rehovot, Israel)}

I agree with Dr. Forssberg. It does not seem to be possible to differentiate between the actual goaldirected movement and its accompanying postural adjustment. Wouldn't the conclusion be that we cannot test the one without the other? Which means that we should not aim at an isolated clinical evaluation of postural control. Wouldn't it be better to assess the way movements are carried out?

\section{CEREBELLAR DEVELOPMENT AND POSTURAL CONTROL}

\section{Albert Gramsbergen (Groningen, the Netherlands)}

Another topic relates to the development of the cerebellum. As known, the cerebellum at adult age 
plays a key role in the fine-tuning of postural adjustments. It has been asked to what extent the development of the cerebellum is dependent upon function. I might start answering this question. An important part of the cerebellar development is late indeed (e.g., Swinny, this issue). The Anlage of the deep cerebellar nuclei and the layer of Purkinje cells is very early in the development of the brain. But, much later, in the human from shortly before birth until well after birth and in rodents even wholly after birth, the precursors of the granular cells, the most numerous neuronal cell type in the brain, start to proliferate from the extragranular layer. These neuroblasts then migrate in an inward direction through the Purkinje cell-layer. The establishment of the connections between these granular cells with the Purkinje cells and also their connections with the climbing fibers that are important in the cerebellar circuitry, occurs largely after birth.

\section{Jerome Swinny (Philadelphia, USA)}

Going back to the question, I am not quite sure whether we could differentiate between morphological development and functional or activitydependent development, as they are closely interlinked. I think all the evidence, which mainly derives from experiments in tissue culture, points to the importance of synaptic activity being important for the development of circuitry. When you remove the afferents or block them you grossly retard the development of the cerebellum (Strata et al, 1997).

\section{Laurent Vinay (Marseille, France)}

If we consider the contribution of the cerebellum in motor control as a link between the CNS and the periphery and muscle contractions than cerebellar functioning obviously requires both the development of ascending and descending fiber systems. In rats, where the control of the brain on the lumbar spinal cord is fully developed by the end of the second postnatal week, it can not be otherwise than that the cerebellum has become functionally important by that time.

Albert Gramsbergen (Groningen, the Netherlands)

Another question was that in the fMRIs during motor tasks, as shown by Dr. Forssberg, no clear indication of any activity in the cerebellum could be observed. The question is how should we interpret this absence of activity or are we dealing with an artifact?

\section{Hans Forssberg (Stockholm, Sweden)}

The fMRIs I presented to you were the very first we made, and at that time the cerebellum was out of view. But actually for the simple squeezing tasks I showed you, that does not really matter. Our more recent research has indicated that the cerebellum is not active during such grasping tasks. But from more recent studies we now know that the cerebellum is very active during more complex motor tasks which need a lot of programming and temporal ordering of the movements which constitute the movement pattern (Bengtsson et al., 2004).

\section{THEORIES ON MOTOR CONTROL: WHAT ABOUT POSTURE?}

\section{Albert Gramsbergen (Groningen, the Netherlands)}

A question from the audience that is remotely related to the former one is the following. As scientific theories are continuously changing and replaced with newer theories, what do practitioners need to know about theories on motor control and why? 


\section{Beatrijs Vereijken (Trondheim, Norway)}

Theories are important because they condense a body of related findings into a coherent framework, allowing for the subsequent building and testing of hypotheses. Every theory operates with a set of assumptions and simplifications that direct further research enterprises. In other words, a theory guides the focus of subsequent research-i.e., which questions will be asked and how these questions are sought to be answered. This in turn, heavily influences the data being collected, the knowledge distilled from it, and the resulting recommendations for applications. When practitioners want to apply these recommendations in their daily practice, they need to be familiar with the background of the theory-its departure points and fundamental assumptions-in order to be able to give the recommendations a proper place in their work.

\section{TRAINING INTENSITY IN CHILDREN WITH CP}

Mijna Hadders-Algra (Groningen, the Netherlands)

Another point of interest: it has been raised that children with $\mathrm{CP}$ need intense raining as these children might have problems in learning specific features of motor control. So the question is, does it really help when the training is intense. Or rather: what is intense?

\section{Andrew Gordon (New York, USA)}

In Dr. Forssberg's group, we tested a child with CP in 1990 when she was 6 years old. Twelve years later, we reassessed the force coordination during grasping in this girl. The reassessment showed that little change had occurred in the force coordination pattern. I am not sure what kind of therapy this child received over the 12 years but despite of the therapy, performance had not changed much. Now I do not mean to imply that this is necessarily completely representative but I think that in general we do not see much improvement in children with CP. Therefore, I believe that at least in some aspects of motor coordination or discoordination you indeed might need intensive training. For instance, in one of our studies on force coordination while lifting an object, we showed that children with CP could change the coordination of anticipation within 25 lifting trials (Gordon \& Duff, 1999), which means that children with CP can learn certain aspects of motor behavior quickly.

In regard to the question of whether or not children with $\mathrm{CP}$ can learn, I think that when you look at simple control tasks, they have a problem with developing internal models for this control which is perhaps due to the impaired sensation of the movements. Apparently, these children do not develop an appropriate representation of their movements.

\section{Frank de Vries (Beetsterzwaag, the Netherlands)}

Here I would like to add the following. With respect to the motor performance of the girl with CP whose basic pattern of coordination did not change over the years, it might mean that the girl already at the age of 6 years had adopted the best strategy. This could mean that even 12 years of intense therapy would not help her any further in this particular behavior.

\section{Andrew Gordon (New York, USA)}

This is a very good point. A lot of the movement patterns we see in children with $\mathrm{CP}$ may not really be impairments but they may well be adaptive strategies or compensations.

\section{Milivoj Velickovic Perat (Ljubljana, Slovenia)}

When we are talking about intensity, we should consider two points. First, the child should be 
actively and intensely involved in the therapy. Second, it is the quality of training that matters. Intensity, therefore, does not just indicate the duration or the frequency of the therapeutic sessions.

\section{Eugene Rameckers (Valkenburg, the Netherlands)}

In response to both Dr. Velickovic and Dr. Gordon, I would like to say that to my opinion we do need intense therapy. We have to realize that a child, untreated and using the wrong strategy used this strategy for several years many times a day and that the child did or did not succeed in accomplishing a certain task. When we start therapy, we practice for half an hour per day with the child. A very limited amount of practice compared to the years during which the child used the maladaptive strategy and failed to perform the task. Thus I think, we do need very intense therapy to overrule the strategies used for years and years.

\section{Christine Assaiante (Marseille, France)}

Has anyone ever demonstrated a relation between the intensity of training and the benefits for the child?

\section{Susan Harris (Vancouver, Canada)}

Some years ago I performed a literature search and found only nine studies about this issue. Three of these studies showed that the more intense the therapy was, the better the outcome, but the other six studies did not show a difference whatsoever. Happily enough, the performance of the children who had been receiving intense therapy did not get worse either. The person who studied this most is Eva Bower (e.g., Bower et al., 1996, 2001).

Another issue that is important in this respect is bursts of therapy. Rather than training once or twice a week, even when it is for 6 hours, we perhaps should look at specific targeted goals when working intensively with a child. I mean that we perhaps should aim at a specific goal and allow the child to practice and work with that specific goal during an intense bout of training.

\section{Eva Brogren Carlberg (Stockholm, Sweden):}

The recent evidence report of the American Academy for Cerebral Palsy and Developmental Medicine on conductive education and the intensity of different treatments (Darrah et al., 2004) included a study in which children were trained for 13 hours a day, but even in this study, no effect was found; so something must have been terribly wrong there.

Another aspect is retention of learning. Here, it is important to differentiate between the different levels of the GMFCS. Dr. Gordon, who presented pilot data of a study on the effect of constraintinduced therapy in children with hemiplegia, showed that in children who function at GMFCS levels I and II, one problem is learned non-use (see Charles \& Gordon, this issue). When these children receive very intense training they catch up very fast. We see a similar thing in strength training and obviously, there is a good retention (Damiano et al., 2002). So the problem comes when the child has a larger deficit, and is functioning at GMFCS levels III to V. The questions are, 'How much can you learn' and 'What are the limits'? These questions are among the challenges for the future.

\section{Hans Forssberg (Stockholm, Sweden)}

There is not something magically taking place with learning in children with $\mathrm{CP}$. Children with $\mathrm{CP}$ have the same mechanisms of learning and training as in all people and animals. During my lecture, I showed you some studies on the plasticity of cortical maps. These studies showed that these maps are very dynamic. For instance, the monkeys in the studies by Merzenich were trained only for 3 weeks and then only for half an hour or 1 hour a 
day, and this induced quite distinctive reorganizations (e.g., Recanzone et al. 1992). So actually, I think it is more a question of quality and the specificity of the task than the duration or the intensity that makes you learn new movements. I think that is important.

\section{Andrew Gordon (New York, USA)}

I agree with Dr. Forssberg. In our constraintinduced therapy study, we chose an intensity of training that was analogous with that in adult studies. The adult studies seemed to be suggestive at this point that there is an efficacy. That being said, I do not think that in young children intensity is required to achieve changes. So it is probably the quality of practice that is more important. Like Dr. Forssberg mentioned, the ability to learn and the plasticity mechanisms are important factors in therapy in children with $\mathrm{CP}$. However, children with CP differ in one important aspect from typically developing individuals: they have a lesion of the brain. This might mean that the extent to which you can accomplish changes is limited.

Marianne Appelman-Kreuzen (Lelystad, the Netherlands)

The quality and intensity of training very well could be dependent on the motivation of the child and the family to learn a new skill. We still know little about that, but I have the gut feeling that motivation is a key issue.

\section{POSTURE IN CHILDREN WITH CP: DYSFUNCTION OR COMPENSATION?}

Melanie Gibbs (Tadworth, UK)

Could someone please comment on the influence of a reclined posture to increase extensive patterning of the upper-limb retraction. In other words, is a reclined posture a choice or an obligatory posture imposed on the child by the condition?

\section{Eva Brogren Carlberg (Stockholm, Sweden)}

The reclined posture was the posture chosen during reaching by the children with $\mathrm{CP}$ that $\mathrm{I}$ demonstrated in my lecture. Here it is interesting to note that we perhaps deal with differences between sitting and standing. Dr. Woollacott and her colleagues showed in one of their studies that when typically developing children adopted a crouched posture during standing their muscle activation patterns resembled those of children with $\mathrm{CP}$ (Burtner et al., 1998). But in sitting it might be well the other way around. We showed that for children with CP the more crouched sitting position functioned better than the upright sitting posture (Brogren et al., 2001). Thus, I would not say that the reclined position is an obligatory position. It is the posture which the child selects that matters.

\section{Marjorie Woollacott (Eugene, Oregon, USA)}

I do not think that what we found is that the typically developing children looked more like children with $\mathrm{CP}$ when they crouched. That is not to say that a crouched position is not effective or perhaps functional for children with $\mathrm{CP}$.

Reint Geuze (Groningen, the Netherlands):

To draw this discussion in a wider sense, I would like to ask Dr. Brogren the following. You suggested that children with deficits will tenaciously choose a certain sitting position which would be an optimal solution for their problems. However, to my opinion, the spontaneously chosen solutions are not always the best solutions for the tasks the child should be able to perform. In some 
instances an optimal solution is chosen, but in others not. For therapy, this distinction might be very important. So my question is, how could we distinguish between beneficial adaptations and maladaptations?

\section{Eva Brogren Carlberg (Stockholm, Sweden)}

I think this question should be explored by every therapist. So we always need to address the questions, 'What are good compensations'? 'What are compensations that the child needs'? and 'What can be changed with intense therapy'. The big challenge for the therapist is to analyze the compensations and to ask why these are adopted.

\section{Andrew Gordon (New York, USA)}

I think you ask for 10 more years of further research to be done. Latash and Anson (1996) have written a controversial paper. They addressed questions about whether the motor patterns in individuals with movement disorders are compensations that you should try to strengthen or whether they are rather impairments. They took the position that most often you are dealing with a compensation. I agree with Dr. Geuze that perhaps not all compensations necessarily are going to lead to the best function and in those cases, you should train other types of compensation and increase capabilities.

\section{Richard Major (Newcastle upon Tyne, UK)}

To answer the question of what is a good posture, you need to analyze the biomechanics of such postures to really come to an understanding of it. If you want to optimize, I would suggest you to look at minimizing the moments and torques which are present around joints and the reason for that is that you want to minimize energy costs which are involved. I think, basically we all are lazy and every goal we want to achieve should be at minimum energy costs. That might be a good topic for a future meeting.

\section{Reint Geuze (Groningen, the Netherlands)}

I would like to make the suggestion that variable practice will enable the system to find its optimal solutions. Obviously, in children with a motor disorder this practice is limited. This might be the solution to the question I just posed.

\section{Mijna Hadders-Algra (Groningen, the Netherlands)}

Coming to the end of this discussion, which could have continued for a much longer time and to the end of this workshop, we may conclude that several new perspectives for research, for analysis of motor problems in children with motor disorders and inspiration for a fresh start on thinking of our therapies have emerged during this meeting. The interest of basic scientists in the problems which are encountered by the investigators involved in clinical problems and the newly gained knowledge in experimental research which has given way to think of alternative strategies in clinical research were the motivation for organizing this workshop. We feel certain that the contributions of the keynote speakers and the poster presentations, as well as the lively discussions during this workshop have given all of us the inspiration to proceed our research into postural control as a key issue in typical and deviant motor behavior.

\section{REFERENCES}

Assaiante C, Mallau S, Viel S, Jover M, Schmitz. 2005 Neural Plast 20:37-46 (this issue).

Bentsson S, Ehrsson HH, Forssberg H, Ullén F. 2004. Dissociating brain regions controlling the temporal and ordinal structure of learned movement sequences Eur J Neurosci 19: 2591-2602. 
Berg KO, Wood-Dauphinee S, Williams JI. 1995. The balance scale: Reliability assessment with elderly residents and patients with an acute stroke Scand J Rehab Med 27: 27-36.

Bower E, McLellan DL, Arney J, Campbell MJ. 1996. A randomised controlled trial of different intensities of physiotherapy and different goals setting procedures in 44 children with cerebral palsy. Dev Med Child Neurol 38: 226-237.

Bower E, Michell D, Burnett M, Campbell MJ, McLellan DL. 2001. Randomized controlled trial of physiotherapy in 56 children with cerebral palsy followed for 18 months. Dev Med Child Neurol 43: 4-15.

Brogren E, Forssberg H, Hadders-Algra M. 2001. The influence of two different sitting positions on postural adjustments in children with spastic diplegia. Dev Med Child Neurol 43: 534-546.

Bruininks RH. 1978. Bruininks-Oseretsky Test of Motor Proficiency. Circle Pines: American Guidance Service; 1-153.

Burtner PA, Qualls C, Woollacott MH. 1998. Muscle activation characteristics of stance balance control in children with spastic cerebral palsy. Gait Posture 8: 164-174.

Charles J, Gordon AM. 2005. A critical review of constraint-induced therapy and forced-use in children with hemiplegia. Neural Plast 20: 173-189 (this issue).

Damiano DL, Dodd K, Taylor NF. 2002. Should we be testing and training muscle strength in cerebral palsy? Dev Med Child Neurol 44: 68-72.

Darrah J, Watkins B, Chen L, Bonin C. 2004. Conductive education intervention for children with cerebral palsy: an AACPDM evidence report. Dev Med Child Neurol 46: 187-204.

Gordon AM, Duff SV. 1999. Fingertip forces during object manipulation in children with hemiplegic cerebral palsy. I Anticipatory scaling. Dev Med Child Neurol 41: 166-175.

Henderson SE, Sugden DA. 1992. Movement Assessment Battery for Children: Manual. Sidcup, Kent UK: The Psychological Corporation; 128.

Latash ML, Anson JG. 1996. What are 'normal movements' in atypical populations? Behav Brain Sci 19: 55-68.

Palisano R, Rosenbaum P, Walter S, Russell D, Wood E, Galuppi B. 1997. Development and reliability of a system to classify gross motor function in children with cerebral palsy. Dev Med Child Neurol 39: 214-223.

Recanzone GH, Merzenich MM, Jenkins WM, Grajski KA, Dinse HR. 1992. Topographical reorganization of the hand representation in cortical area $3 \mathrm{~b}$ owl monkeys trained in a frequency-discrimination task. J Neurophysiol 67: 1031-1056.

Russell DJ, Rosenbaum P, Avery LM, Lane L. 2002. Gross Motor Function Measure (GMFM-66 \& GMFM-88) users manual. Clin Dev Med No. 159. London, UK: MacKeith Press; 234.

Strata P, Tempia F, Zagrebelsky M, Rossi F. Reciprocal trophic interactions between climbing fibres and Purkinje cells in the rat cerebellum. Prog Brain Res 1997; 114: 263-282

Swinny JD, Van der Want JJL, Gramsbergen A. 2005. Cerebellar development and plasticity: perspectives for motor coordination strategies, for motor skills and for therapy. Neural Plast 20: 81-88 (this issue).

Woollacott MH, Shumway-Cook A. 2005. Postural dysfunction during standing and walking in children with cerebral palsy: what are the underlying problems and what new therapies improve balance. Neural Plast 12: 139-148 (this issue). 

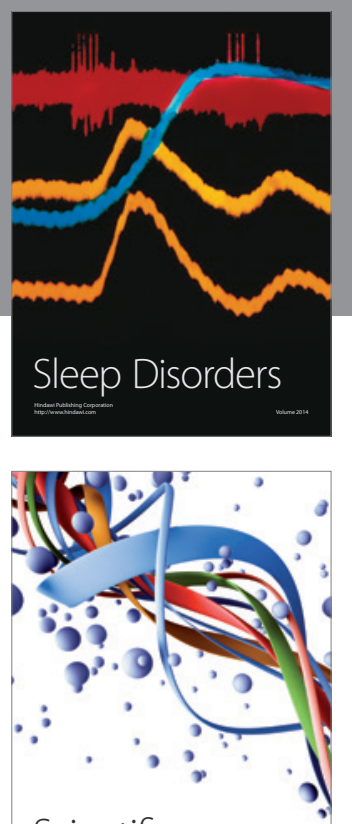

Scientifica
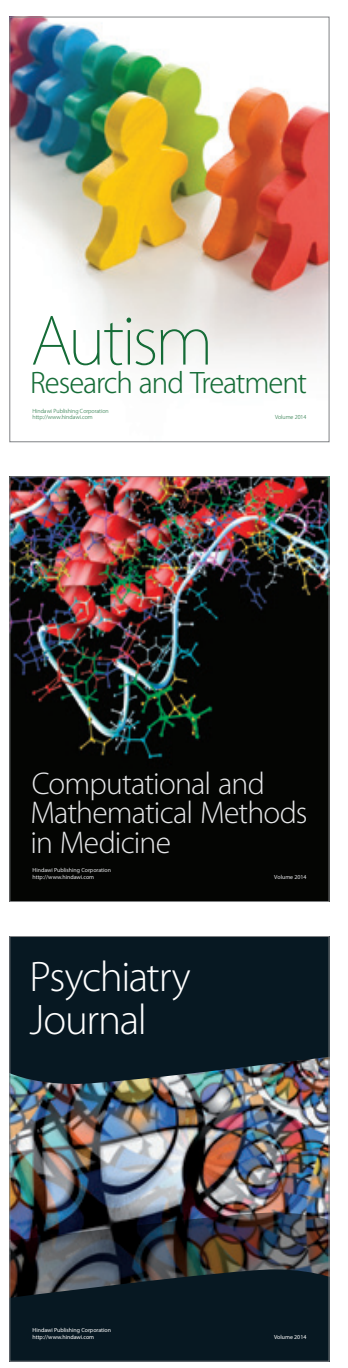
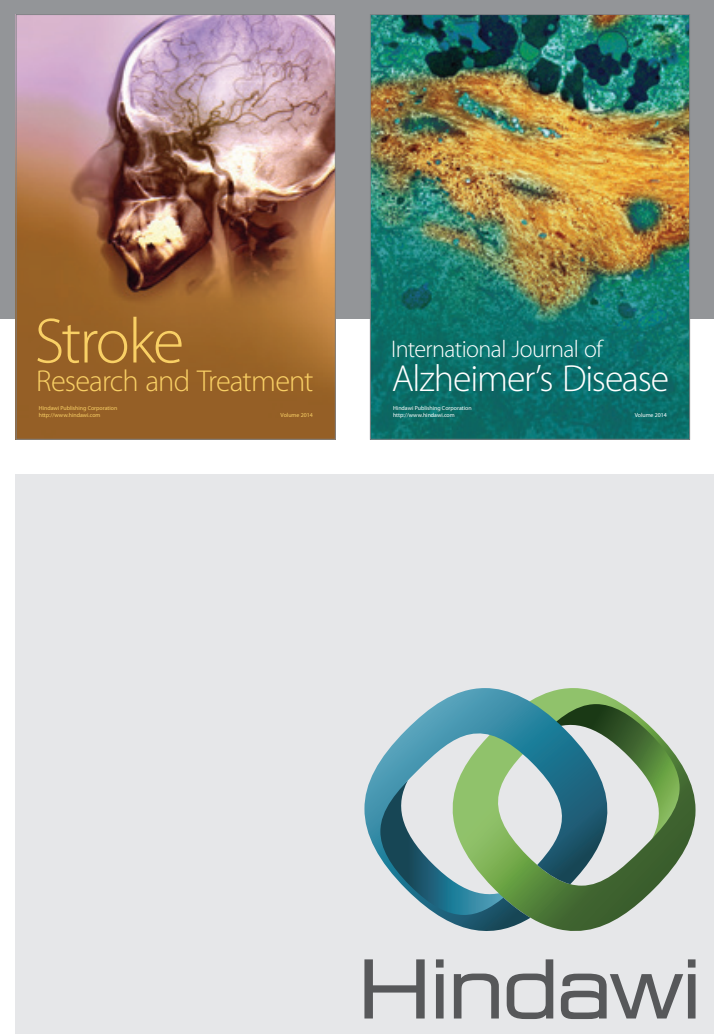

Submit your manuscripts at

http://www.hindawi.com
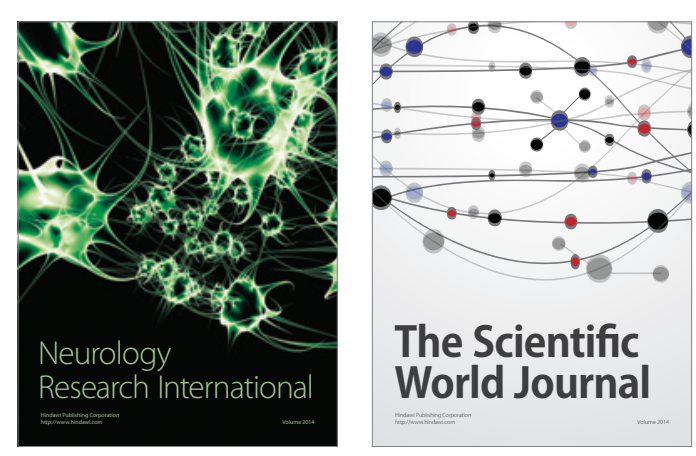

The Scientific World Journal

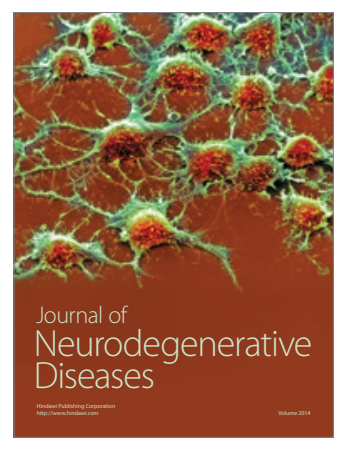

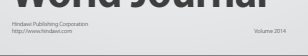

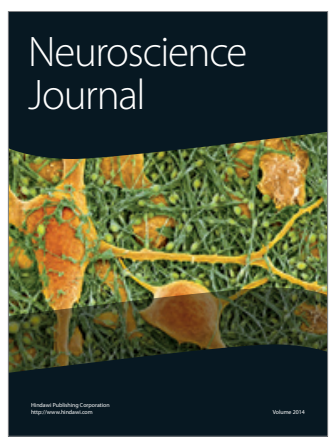

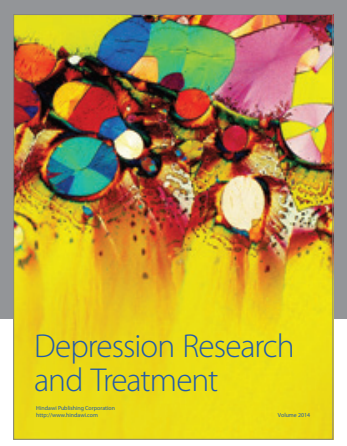
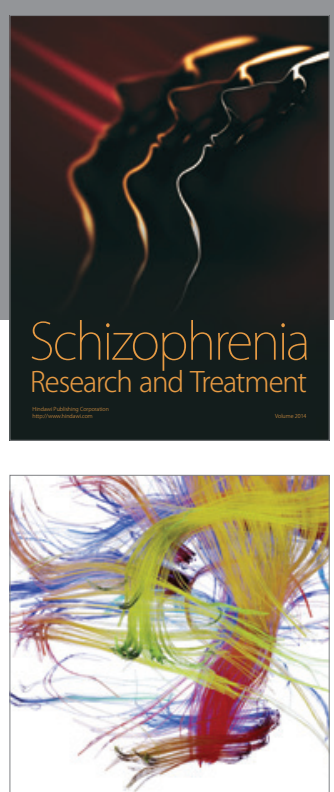

Brain Science

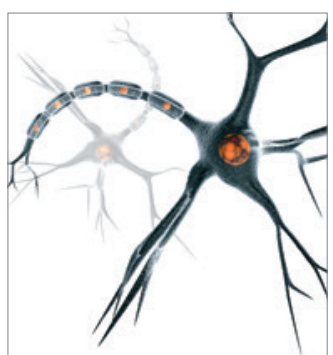

Neural Plasticity
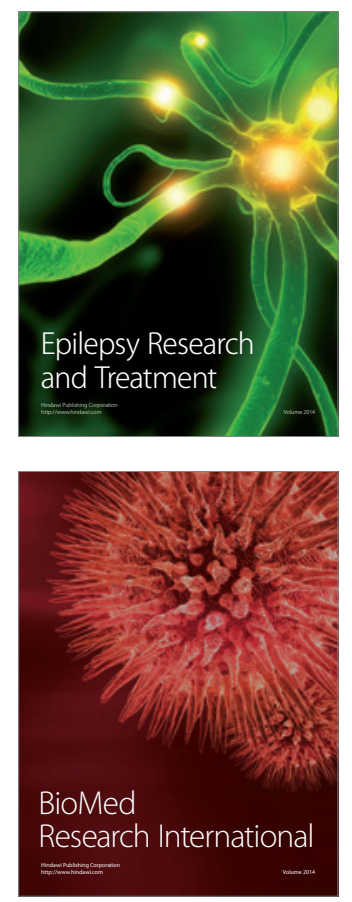

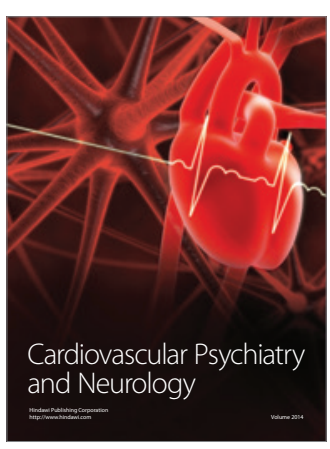

Parkinson's

Disease
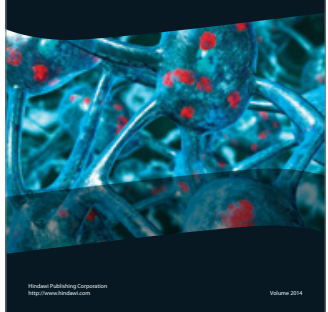